\title{
A dança sênior como recurso terapêutico para idosos
}

\author{
Fernanda Antico Benetti \\ Curso de Fisioterapia, Faculdade de Medicina do ABC (FMABC) - Santo André (SP), Brasil. \\ E-mail: benetti.fernanda@gmail.com
}

DOI: http://dx.doi.org/10.7322/abcshs.v40i1.695

O processo de envelhecimento é acompanhado de diversas alterações físicas e cognitivas que, em geral, acarretam prejuízos funcionais, emocionais e sociais. O idoso sofre diversas transformações em sua vida cotidiana e, em decorrência desses fatos, torna-se necessário desenvolvermos estratégias que possibilitem qualidade de vida a esses idosos. Uma estratégia que está ganhando espaço no Brasil é a Dança Sênior.

A Dança Sênior surgiu em 1974, na Alemanha, sendo liderada por Ilse Tutt, onde, em 1977, foi fundada a Federação Nacional de Dança Sênior. Mais tarde, em 1978, Christel Weber trouxe a dança para o Brasil e, a partir de 1982, passou a ser aplicada no Ancianato Bethesda. Em 1993, foi criada a Associação de Dança Sênior em Pirabeiraba (SC).

Segundo a Associação de Dança Sênior ${ }^{1}$, com sua prática, buscam-se autoestima e integração do grupo, promovendo o bem-estar dos participantes. A dança trabalha com o corpo através de coreografias criadas a partir de músicas instrumentais e movimentos ritmados. É realizada em grupo e com seus participantes em círculo, ora sentados, ora em pé; ora em pares, em fileiras ou dispersos pelo salão. As coreografias são ensinadas, de forma padronizada, às pessoas que serão dirigentes de novos grupos. Trata-se de uma atividade socializante, valiosa para pessoas idosas, pois desenvolve a vida em comunhão com outros. Melhora a autoestima do idoso por se sentir ativo e participativo, ainda que apresente limitações típicas de idade avançada. O movimento estimula a motricidade e a mobilidade das articulações, proporcionando uma melhor coordenação motora e maior segurança através do domínio do corpo. A respiração estimulada e a circulação sanguínea intensificada favorecem uma melhor oxigenação e irrigação das células, prevenindo problemas cardiovasculares. A memorização de passos e figuras e o constante treino da coordenação motora desenvolvem a capacidade cognitiva, evitando, assim, o desgaste precoce do reflexo mental e permitindo a manutenção da capacidade intelectual.

A Dança Sênior é uma atividade lúdica e motivante, que surge em meio a diversos recursos terapêuticos, usada como estratégia preventiva da inatividade para retardar a senilidade e promover a qualidade de vida entre os idosos. É uma opção de atividade sócio-físico-mental e emocional, sendo feita em grupos, de baixo impacto, curta duração e que não requer esforços intensos. Suas coreografias podem ser realizadas em ortostase ou sedestação, proporcionando a manutenção da amplitude de movimento, o aumento da flexibilidade, mobilidade e agilidade. A dança com idosos sentados integra os participantes no convívio de um grupo maior. É uma atividade que pode ser aplicada também para idosos com limitações, ou sentados em cadeiras de rodas, segundo Carvalho et al. ${ }^{2}$, que, em seu estudo, avaliaram através de questionários a qualidade de vida de pacientes hemiparéticos pós-AVE, antes e após terapia com Dança Sênior. As sessões de terapia com a dança tiveram duração de uma hora, duas vezes por semana, totalizando 24 sessões. Ao final, os questionários foram reaplicados e observou-se diferença estatisticamente significante na melhora da qualidade de vida dos participantes.

Trata-se de um método facilitador para trabalhar com o idoso, trazendo resultados benéficos também em relação ao equilíbrio e às atividades de vida diárias dos praticantes dessa atividade, como mostram os achados de Silva e Berbel ${ }^{3}$, que aparecem neste fascículo da ABCS Health Sciences. Neste estudo, participaram do grupo de Dança Sênior idosos entre 60 e 85 anos, que responderam a escalas de equilíbrio e de atividades de vida diárias. A Dança Sênior foi aplicada duas vezes por semana, durante três meses e, ao final desse período, foram refeitas as duas escalas citadas. A partir dos achados deste estudo, foi possível identificar que a prática de dança trouxe melhora do equilíbrio e das atividades de vida diárias.

Segundo Cassiano et al. ${ }^{4}$, a Dança Sênior é uma atividade grupal que cria um ambiente de experiências enriquecedoras, no qual habilidades pessoais e interpessoais podem ser exploradas, reforçando-se a autoestima. Os componentes sensório-motores, tais como: a mobilidade, a flexibilidade e coordenação, podem ser trabalhados visando à manutenção ou melhora. Os componentes cognitivos, tais como atenção, nível de concentração e retenção, podem ser otimizados. Essas características, associadas, contribuem para o desenvolvimento do indivíduo, bem como para a sensação de bem-estar e saúde. Trata-se de um agente facilitador de maior adesão dos indivíduos idosos à prática de uma atividade física, podendo produzir benefícios tanto físicos e cognitivos quanto emocionais e sociais. O uso da Dança Sênior como recurso no atendimento terapêutico ocupacional a idosos hígidos propicia autonomia, autoconhecimento e ressignificação do cotidiano. Dessa maneira, pode ser considerado um dispositivo terapêutico, na medida em que facilita e favorece a vivência grupal, ampliando o suporte social e estimulando as funções físicas e cognitivas, gerando também benefícios emocionais e sociais. Neste estudo, a Dança Sênior foi aplicada durante um ano, com frequência semanal e duração de uma hora, em um grupo de 20 idosos com faixa etária entre 65 e 84 anos. 
Além disso, um estudo realizado por Kudlacek et al. ${ }^{5}$ investigou se a Dança Sênior apresenta efeitos sobre a densidade mineral óssea de idosas com e sem osteoporose, mostrando um considerável aumento da densidade mineral óssea na região lombar das participantes com osteoporose, enquanto que as participantes sem osteoporose mantiveram seus níveis de densidade inalterados.

Ainda são escassos os estudos sobre os impactos da terapia com a Dança Sênior nas alterações causadas pelo envelhecimento; no entanto, o que temos até então nos mostra benefícios na esfera física, social, cognitiva e uma melhora na percepção da qualidade de vida, o que nos leva a acreditar que a Dança Sênior pode ser utilizada como uma estratégia de promoção da percepção de bem-estar e saúde de idosos.

\section{REFERÊNCIAS}

1. Associação de dança sênior [Internet]. O que é dança sênior? Disponível em: http://www.portalbethesda.org.br/danca_senior. htm. Acesso em: 25 mar. 2015.

2. Carvalho PC, Santos LA, Silva SM, Cavalli SS, Corrêa JC, Corrêa FI. Avaliação da qualidade de vida antes e após terapia com dança sênior em pacientes hemiparéticos pós-AVE. ConScientiae Saúde. 2012;11(4):573-9.

3. Silva AFG, Berbel AM. O benefício da dança sênior em relação ao equilíbrio e às atividades de vida diárias no idoso. ABCS Health Sci. 2015;40(1):16-21.

http://dx.doi.org/10.7322/abcshs.v40i1.698
4. Cassiano JG, Serelli LS, Cândido AS, Torquetti A, Fonseca K. Dança sênior: um recurso na intervenção terapêutico-ocupacional junto a idosos hígidos. RBCEH. 2009;6(2):204-12. http://dx.doi.org/10.5335/rbceh.2009.019

5. Kudlacek S, Pietschmann F, Bernecker P, Resch H, Willvonseder R. The impact of a senior dancing program on spinal and peripheral bone mass. Am J Phys Med Rehabil. 1997;76(6):477-81. 